\title{
Risk Factors Associated with Acute Coronary Syndrome after Successful Percutaneous Coronary Intervention
}

\author{
Violeta Dinesch ${ }^{1 *}$, Mihail Dinesch², lleana Voichita Sirbu³, Cosmin Macarie3, Mircea Buruian ${ }^{4}$ \\ 1. University of Medicine and Pharmacy Tîrgu Mures, Romania \\ 2. Department of Cardiology, Institute for Cardiovascular Disease and Heart Transplant, Tîrgu Mures, Romania \\ 3. Department of Internal Medicine M3, University of Medicine and Pharmacy, Tîrgu Mures, Romania \\ 4. Department of Morphologic Sciences M1, University of Medicine and Pharmacy Tîrgu Mures, Romania
}

Objective: Admission for acute coronary syndrome after successful percutaneous coronary intervention is a delicate situation for the patient and doctor. Predictors of these cases are poorly described. Methods: We retrospectively analysed the files of post-percutaneous coronary intervention patients admitted to the Department of Cardiology of the Institute for Cardiovascular Disease and Heart Transplant in Tirgu Mures between January 2012 and December 2015. Analyses using the t-test, chi-square test, and Fisher test were performed to compare demographics, clinical and angiographic characteristics of patients with acute coronary syndrome, patients with stable angina, and those without symptoms. Results: One hundred eighty post-percutaneous coronary intervention patients were readmitted; 46 patients (25.55\%) were readmitted for acute coronary syndrome. Histories of arterial hypertension and renal dysfunction at hospital admission were associated with acute coronary syndrome. Bare metal stent in-stent restenosis and localisation of bare metal stent in-stent restenosis of the left descendent coronary artery were angiographic predictors of acute coronary syndrome. Conclusion: Several clinical and angiographic factors identify patients at high risk for acute coronary syndrome after successful percutaneous coronary intervention. Recognition and treatment of these factors may prevent readmission for such a dangerous condition and may improve outcomes.

Keywords: acute coronary syndrome, percutaneous coronary intervention, in-stent restenosis

Received 15 September 2017 / Accepted 8 November 2017

\section{Introduction}

Coronary artery stents, both bare metal stents and drugeluting stents, significantly reduce the incidence of events related to culprit lesion treated during the first (index) percutaneous coronary intervention; however, coronary artery disease is a continuous process. Reoccurrence of symptomatology, particularly acute coronary syndrome, is a challenging situation because acute coronary syndrome is still a major cause of death and has a high economic burden. Identification of factors that could predict the development of acute coronary syndrome, especially preventable factors, would be extremely useful for the clinical management of these patients.

\section{Methods}

This was a single-centre retrospective analysis of 180 readmitted post-percutaneous coronary intervention patients over a 4-year period (January 2012-December 2015). Patients were divided into three groups: acute coronary syndrome patients, patients with stable angina, and asymptomatic patients. Baseline characteristics, cardiac history, risk factors, comorbidities, results of coronarography at the index percutaneous coronary intervention and at readmis-

\footnotetext{
* Correspondence to: Violeta Dinesch
}

E-mail: doc_violeta@yahoo.com sion, stent type used at the index percutaneous coronary intervention, and medication after percutaneous coronary intervention were compared between the three subgroups.

\section{Statistical analysis}

Continuous variables were expressed as mean \pm standard deviation and compared using t-tests. Categorical variables were presented as numbers and percentages and compared using chi-square or Fisher tests. A p-value $<0.05$ was considered statistically significant. All statistical analyses were performed using STATA 14.0 (Stata Corporation, College Station, TX, USA).

\section{Results}

Forty-six (25.55\%) patients with acute coronary syndrome, $101(56.11 \%)$ patients with stable angina, and 33 (18.33) asymptomatic patients were readmitted after successful percutaneous coronary intervention (Table I).

Patients with acute coronary syndrome were older than asymptomatic patients $(63.93 \pm 10.69$ vs. $58.87 \pm 9.25$ years; $\mathrm{p}=0.031$ ) and more often had a history of myocardial infarcts than patients with stable angina $(\mathrm{p}=0.005)$.

Arterial chronic hypertension and impaired renal function (estimated glomerular filtration rate $\leq 60 \mathrm{ml} / \mathrm{min}$ ) were more frequent in the acute coronary syndrome group than in the other two groups. There were no other differences 
Table I. Baseline characteristics, cardiovascular risk factors, and comorbidities

\begin{tabular}{|c|c|c|c|c|c|}
\hline & \multicolumn{2}{|c|}{ Stable angina group } & \multicolumn{2}{|c|}{ Asymptomatic group } & \multirow{2}{*}{$\begin{array}{l}\text { ACS group } \\
46(25.55 \%)\end{array}$} \\
\hline & $101(56.11 \%)$ & ${ }^{*} \mathbf{p}$ & $33(18.33 \%)$ & ${ }^{*} \mathbf{p}$ & \\
\hline Age, years & $61.97 \pm 9.72$ & 0.273 & $58.87 \pm 9.25$ & 0.031 & $63.93 \pm 10.69$ \\
\hline Male, n (\%) & 76 (75.25) & 0.652 & 27 (81.82) & 0.301 & 33 (71.74) \\
\hline HTN, n (\%) & $93(92.8)$ & 0.057 & $29(87.88)$ & 0.027 & $46(100)$ \\
\hline Diabetes mellitus, n (\%) & $19(18.81)$ & 0.066 & $6(18.18)$ & 0.152 & $15(32.61)$ \\
\hline Obesity, n (\%) & $28(27.72)$ & 0.946 & $10(30.3)$ & 0.844 & $13(28.26)$ \\
\hline Dyslipidemia, n (\%) & $50(49.5)$ & 0.586 & $12(36.36)$ & 0.114 & $25(54.25)$ \\
\hline Smoker, n (\%) & $14(13.86)$ & 0.578 & $4(12.12)$ & 0.752 & $8(17.39)$ \\
\hline eGFR $\leq 60 \mathrm{ml} / \mathrm{min}, \mathrm{n}(\%)$ & 20 (19.8) & 0.006 & $4(12.12)$ & 0.006 & $19(41.3)$ \\
\hline Previous MI, n (\%) & $43(42.57)$ & 0.005 & $18(54.55)$ & 0.246 & 31 (67.39) \\
\hline Previous CABG, n (\%) & $6(5.94)$ & 1 & 0 & 0.261 & $3(6.52)$ \\
\hline
\end{tabular}

${ }^{*} \mathrm{p}$ compared with ACS group.

ACS, acute coronary syndrome; HTN, hypertension; MI, myocardial infarction; CABG, coronary artery bypass grafting; eGFR, estimated glomerular filtration rate.

in baseline characteristics, risk factors, and comorbidities between the three groups.

Right coronary artery disease was more frequent in the acute coronary syndrome group than in the other two groups; however, the numbers of diseased vessels between the three groups at the index procedure or readmission were not different. Drug-eluting stent utilisation at index percutaneous coronary intervention was more frequent in the asymptomatic group. Bare metal stent in-stent restenosis and localisation of in-stent restenosis to the left descending artery occurred more often in the acute coronary syndrome group than in the stable angina group or asymptomatic group (Table II).

\section{Discussion}

Arterial chronic hypertension is a classical and well-known cardiovascular risk factor for the development of atherosclerosis and coronary artery disease. A previous study revealed a $63.4 \%$ prevalence of hypertension among acute coronary syndrome patients [1]. The impact of hypertension on patients with acute coronary syndrome is related to the progression of coronary atherosclerosis and favours the

Table II. Intervention features

\begin{tabular}{|c|c|c|c|c|c|c|}
\hline & & \multicolumn{2}{|c|}{ Stable angina group } & \multicolumn{2}{|c|}{ Asymptomatic group } & \multirow{2}{*}{$\begin{array}{c}\text { ACS group } \\
\text { N (\%) }\end{array}$} \\
\hline & & $\mathbf{N}(\%)$ & $\mathbf{p}^{*}$ & $\mathbf{N}(\%)$ & $\mathbf{p}^{*}$ & \\
\hline \multirow[t]{4}{*}{ Number of diseased vessels at index $\mathrm{PCl}$} & 1 & $50(49.5)$ & 0.301 & $10(30.3)$ & 0.279 & $18(39.13)$ \\
\hline & 2 & $32(31.68)$ & & $15(45.45)$ & & $16(34.78)$ \\
\hline & 3 & $16(15.84)$ & & $6(18.18)$ & & $12(26.09)$ \\
\hline & $>3$ & $3(2.97)$ & & $2(6.06)$ & & 0 \\
\hline \multirow[t]{5}{*}{ Lesion localisation at index $\mathrm{PCl}$} & LMCA & $3(2.97)$ & 0.377 & 0 & 0.261 & $3(6.52)$ \\
\hline & LAD & $70(69.31)$ & 0.569 & $24(72.37)$ & 0.906 & $34(73.91)$ \\
\hline & $\mathrm{RCA}$ & $40(39.6)$ & 0.056 & $19(57.58)$ & 0.926 & $26(56.52)$ \\
\hline & LCX & $35(34.65)$ & 0.808 & $10(30.3)$ & 0.828 & $15(32.61)$ \\
\hline & Other coronary artery & $24(23.76)$ & 0.385 & $11(33.33)$ & 0.102 & $8(17.39)$ \\
\hline \multicolumn{2}{|c|}{ Time interval between index $\mathrm{PCl}$ and readmission (mean \pm median), months } & $27.68 \pm 29.66$ & 0.07 & $24.33 \pm 35.12$ & 0.09 & $37.86 \pm 35.52$ \\
\hline \multirow[t]{4}{*}{ Number of diseased vessel at readmission } & 0 & $45(44.55)$ & 0.087 & $15(45.45)$ & 0.142 & $11(23.91)$ \\
\hline & 1 & $37(36.63)$ & & $14(42.42)$ & & $21(45.65)$ \\
\hline & 2 & $14(13.86)$ & & $3(9.09)$ & & $10(21.74)$ \\
\hline & 3 & $5(4.95)$ & & $1(3.03)$ & & $4(8.7)$ \\
\hline \multirow[t]{5}{*}{ Lesion localisation at readmission } & LMCA & $2(1.98)$ & 0.589 & 0 & 0.507 & $2(4.35)$ \\
\hline & LAD & $22(21.78)$ & 0.161 & $6(18.18)$ & 0.152 & $15(32.61)$ \\
\hline & $\mathrm{RCA}$ & $22(21.78)$ & 0.028 & $6(18.18)$ & 0.046 & $18(39.13)$ \\
\hline & LCX & $7(6.93)$ & 0.226 & $5(15.15)$ & 1 & $6(13.04)$ \\
\hline & Other coronary artery & $21(20.79)$ & 0.476 & $6(18.18)$ & 0.409 & $12(26.09)$ \\
\hline \multirow[t]{2}{*}{ Stent type at index $\mathrm{PCl}$} & DES & $34(33.66)$ & 0.081 & $16(48.48)$ & 0.006 & $9(19.57)$ \\
\hline & BMS & $77(76.24)$ & 0.239 & $23(69.7)$ & 0.108 & 39 (84.78) \\
\hline DES ISR, n (\%) & & $4(3.96)$ & 0.258 & 0 & 0.136 & $4(8.7)$ \\
\hline BMS ISR, n (\%) & & $34(33.66)$ & 0.033 & $6(18.18)$ & 0.002 & $24(52.17)$ \\
\hline \multirow[t]{4}{*}{ BMS ISR localisation } & LMCA & $10(9.9)$ & 0.052 & $1(3.03)$ & 0.021 & $10(21.47)$ \\
\hline & $\mathrm{RCA}$ & $8(7.92)$ & 1 & $2(6.06)$ & 1 & $3(6.52)$ \\
\hline & LCX & $6(5.94)$ & 1 & $1(3.03)$ & 0.636 & $3(6.52)$ \\
\hline & Other coronary artery & $3(2.97)$ & 0.648 & $1(3.03)$ & 1 & $2(4.35)$ \\
\hline
\end{tabular}


development of vulnerable atherosclerotic plaques through which rupture can occur during acute coronary syndrome. The prognoses of patients with known hypertension and acute coronary syndrome are also impaired. In the Kamir registry, a history of hypertension was related to higher inhospital mortality [2]. In the GISSI-2 study, in-hospital and 6-month mortality rates were higher for hypertensive patients than for normotensive myocardial infarction patients [3].

Chronic kidney disease is associated with accelerated atherosclerosis and is a predictor of cardiovascular morbidity, mortality, and all-cause mortality for patients with acute coronary syndrome $[4,5]$. Mechanisms related to the adverse outcomes are more severe vessel disease on presentation with acute coronary syndrome [4], differences in coronary plaque morphology [6], less aggressive revascularization, and medical therapy.

The superiority of drug-eluting stents compared to bare metal stents regarding target lesion revascularisation has been investigated in many studies. In NORSTENT, the largest randomised study to compare contemporary drugeluting stents and bare metal stents, target lesion revascularisation and definite stent thrombosis were significantly lower for drug-eluting stent patients than for bare metal stent patients [7]. Furthermore, in our study, bare metal stent in-stent restenosis was more frequent than drugeluting stent in-stent restenosis in the acute coronary syndrome group. These findings raise the question of the utility of bare metal stents in the era of drug-eluting stents and bioabsorbable vascular stents. High haemorrhagic risk and inadequate dual antiplatelet therapy may be reasons why bare metal stents are preferred to drug-eluting stents.

The localisation of bare metal stent in-stent restenosis was not unusual because tortuosity and angulation of the left descending coronary artery can predispose patients to accelerated progression of atherosclerosis [8.9].

Right artery disease was more frequent in the acute coronary syndrome group than in the other two groups at readmission. This raised the hypothesis of incomplete revascularisation at index percutaneous coronary intervention or progression of atherosclerosis after index percutaneous coronary intervention.

\section{Study limitations}

Our study had several limitations. First, the data were retrospectively extracted by reviewing medical observation files and depended on the accuracy and completeness of them. Second, the study included only patients admitted to our clinic. Patients admitted to other hospitals or who died were not included in our study. Finally, the time interval between index percutaneous coronary intervention and readmission has not been standardized. However, the average time interval for each group was not statistically significant.

\section{Conclusion}

Hypertension and impaired renal function are clinical risk factors for acute coronary syndrome. Right coronary artery disease, bare metal stent in-stent restenosis, and left descending artery localisation of bare metal stent in-stent restenosis are angiographic risks associated with acute coronary syndrome. Recognition and treatment, particularly of preventable factors, may improve the outcomes and prognoses of coronary disease patients after successful percutaneous coronary intervention.

\section{Acknowledgments}

This research did not receive any specific grant from funding agencies in the public, commercial, or not-for-profit sectors.

\section{Conflict of interest}

None to declare.

\section{References}

1. Dorobantu M, Tautu OF, Fruntelata A, et al - Hypertension and acute coronary syndromes in Romania: data from the ISACS-TC registry. Eur Heart J Suppl. 2014;16:A20-A27.

2. Kim JH, Chae SC, Oh DJ, et al - Multicenter cohort study of acute myocardial infarction in Korea-interim analysis of the Korea acute myocardial infarction registry-national institutes of health registry. Circ J. 2016;80:1427-1436.

3. Fresco C, Avanzini F, Bosi S, et al - Prognostic value of a history of hypertension in 11,483 patients with acute myocardial infarction treated with thrombolysis. GISSI-2 Investigators. Gruppo Italiano per lo Studio della, Sopravvivena nell'Infarto Miocardico. J Hypertens. 1996;14:743750.

4. Hadadi L, Somkereki C, Dobreanu D. Renal dysfunction at hospital admission, high complexity of coronary artery disease and short term prognosis in acute ST-segment elevation myocardial infarction. Rev Romana Med Lab. 2012;20:363-369.

5. Washam JB, Herzog CA, Beitelshees AL, et al - Pharmacotherapy in chronic kidney disease patients presenting with acute coronary syndrome: a scientific statement from the American Heart Association. Circulation. 2015;131:1123-1149.

6. Baber U, Stone GW, Weisz G, et al - Coronary plaque composition, morphology, and outcomes in patients with and without chronic kidney disease presenting with acute coronary syndromes. JACC CardiovasC Imaging. 2012;5(3 Suppl):S53-S61.

7. Bønaa K, Mannsverk J, Wiseth R, et al - Drug-eluting or bare-metal stents for coronary artery disease. N Engl J Med. 2016;375:1242-1252.

8. Wasilewski J, Niedziela J, Osadnik T, et al - Predominant location of coronary artery atherosclerosis in the left anterior descending artery. The impact of septal perforators and the myocardial bridging effect. Kardiochir Torakochirurgia Pol. 2015;12:379-385.

9. Zou Y, Huang X, Feng L, et al - Localization of in-stent neoatherosclerosis in relation to curvatures and bifurcations after stenting. $J$ Thorac Dis. 2016;8:3530-536. 